\title{
ERRATUM
}

\section{Spiralled patchwork in pottery manufacture and the introduction of farming to Southern Europe-ERRATUM}

Louise Gomart, Allon Weiner, Marzia Gabriele, Gilles Durrenmath, Sabine Sorin, Lucia Angeli, Marta Colombo, Cristina Fabbri, Roberto Maggi, Chiara Panelli, Didier F. Pisani, Giovanna Radi, Carlo Tozzi \& Didier Binder

Published by Cambridge University Press, 6 December 2017.

Due to an editorial error, part of Figure 1 was omitted from the article by Gomart et al. The corrected figure is reproduced here.

\section{Full citation}

Gomart, L., A. Weiner, M. Gabriele, G. Durrenmath, S. Sorin, L. Angeli, M. Colombo, C. Fabbri, R. Maggi, C. Panelli, D.F. Pisani, G. Radi, C. Tozzi \& D. Binder. 2017. Spiralled patchwork in pottery manufacture and the introduction of farming to Southern Europe. Antiquity 91: 1501-14. https://doi.org/10.15184/aqy.2017.187 

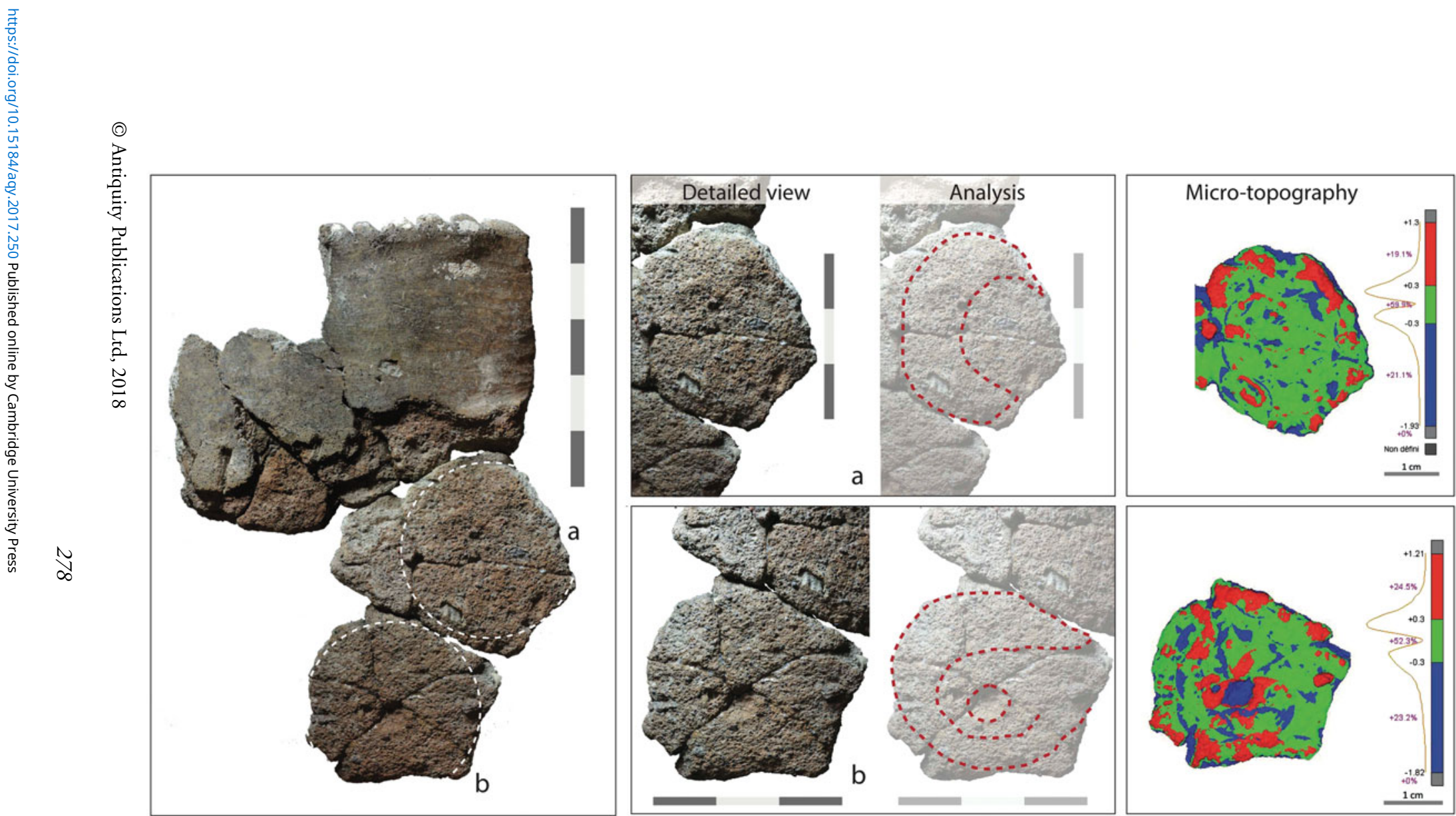

Figure 1. Ceramic macroscopic analysis identifies spiralled patchwork technology. Examination of the ceramics of Abri Pendimoun was conducted by direct observation and microtopographic mapping of the sherds' surfaces. All ceramics $(n=126)$ exhibit networks of circular fractures occurring along the edges of juxtaposed patches. A representative sherd with two highlighted patches $(A$ and $B$ ) is presented. Circular fractures (white dashed lines) delineate the edge of each patch. Arced discontinuities are observed within the patches (red dashed lines). Micro-topographic mapping of the highlighted patches also shows arced discontinuities (blue). Together these suggest the use of a spiralled coil to form each juxtaposed patch. Scale bars are $5 \mathrm{~cm}$ (left panel) and $3 \mathrm{~cm}$ (middle panels). 